\title{
Evaluation of total phenolic content, free radical scavenging activity and phytochemical screening of different extracts of Averrhoa bilimbi (fruits)
}

\author{
*Md. Hasanuzzaman, Md. Ramjan Ali, Marjan Hossain, Sourov Kuri, Mohammad Safiqul Islam \\ Department of Pharmacy, Noakhali Science and Technology University, Sonapur, Noakhali-3814, Bangladesh
}

\begin{abstract}
The present study was designed to investigate the phytochemical screening, the free radical scavenging activity and to determine the total phenolic content of methanolic extract and different solvent soluble fractions of Averrhoa bilimbi Linn. (Oxalidiaceae) fruits. The free radical scavenging activity was evaluated by analyzing the bleaching rate of 1,1diphenyl-2-picrylhydrazyl (DPPH), and total phenolic content was determined by using Folin-Ciocalteau reagent, which results were expressed in gallic acid equivalent (mg of GAE/g of sample). The phytochemical screening revealed the potent source of different phytochemical constituents on different extractives including, phenol, flavonoid, tannin that are responsible for antioxidant action. In the determination of total phenolic content, different extractives showed a significant content of phenolic compounds ranging from 50.23-68.67 mg of GAE/g of extractive. The plant sample displayed significant DPPH free radical scavenging activity with highest $\mathrm{IC}_{50}$ value in crude methanolic extract $(30.365 \mu \mathrm{g} / \mathrm{ml})$ followed by chloroform, carbon tetrachloride, pet-ether and aqueous soluble fractions having value of $32.852 \mu \mathrm{g} / \mathrm{ml}, 36.708 \mu \mathrm{g} / \mathrm{ml}, 50.35 \mu \mathrm{g} / \mathrm{ml}$, and $79.918 \mu \mathrm{g} / \mathrm{ml}$, respectively as opposed to that of the scavenging effects of BHT of $19.656 \mu \mathrm{g} / \mathrm{ml}$.
\end{abstract}

Key Words: Phytochemical screening, antioxidant activity, total phenolic content, gallic acid, DPPH, and IC50.

\section{INTRODUCTION}

Auto-oxidation of lipids, as well as reactive nitrogen species (RNS) is the main source of reactive oxygen species (ROS) in the forms of superoxide anions, hydroxyl radicals and hydrogen peroxide (Aruoma, 1996). Generation of these excess ROS and RNS by Ultraviolet (UV) radiation, smoking and drug metabolisms are likely to damage several cellular components such as lipids, proteins, nucleic acids, and DNAs through the oxidation or nitration processes (Sawa et al., 2000). In addition, these reactive oxygen species cause inflammation or lesion on different organs and are related with various degenerative diseases, including cancer, ageing, arteriosclerosis, and rheumatism (Choi et al., 2002).

All aerobic organisms, including human beings, possesses antioxidant defenses that protect against

\footnotetext{
*Corresponding Author:

Md. Hasanuzzaman

Lecturer, Department of Pharmacy

Noakhali Science and Technology University

Sonapur, Noakhali- 3814, Bangladesh

E-mail: hasanprdu@gmail.com

Contact No.: +8801715758888
}

oxidative damages, frequent damage removal and repair enzymes to eliminate or repair damaged molecules (Yildirim et al., 2001). However, many have been reported that these natural antioxidant mechanisms can be inefficient (Halliwel, 1994; Terao et al., 1994; Moure et al., 2011.). Although some synthetic antioxidant, including butylated hydroxyanisole (BHA) and butylated hydroxytoluene (BHT) are commonly used in processed foods, which have some adverse effects (Kehrer et al., 1990). Therefore, recent search to discover natural originated antioxidant has been increased.

Averrhoa bilimbi Linn. belonging to the family Oxalidiaceae has some local name include belembu, belemburi; In English, this is also known as- bilimbi, cucumber tree, tree sorrel etc. This is attractive, long-lived tropical tree, reaches 16 to $33 \mathrm{ft}$. $(5-10 \mathrm{~m})$ in height; has a short trunk soon dividing into a number of upright branches. Probably, A. bilimbi is native of Moluccas in Indonesia. This plant is also found semi-wild throughout, Brazil, Cuba, Philippines, Sri Lanka, Bangladesh, Myanmar (Burma) and Malaysia. A. bilimbi is used as traditional 
medicine for treating cough, cold, itches, boils, rheumatism, syphilis, diabetes, whooping cough, and hypertension in Asia (Goh et al., 1995; Mackeen et al., 1997). A. bilimbi is also used in the treatment of children's cough (syrup of flowers), stomach ache (fruits) and as a cooling drink (juice of preserved fruits). Earlier studies showed that ethanolic leaf extract of A. bilimbi and its semi-purified fractions possesses hypoglycemic and hypolipidemic properties in Type I diabetic rats when administered intraperitoneally (Tan et al., 1996) as well as orally (Pushparaj et al., 2000).

A survey of the published literature shows that there is a number of research works for the assessment of total phenolic content determination and antioxidant activity of Averrhoa bilimbi fruits using its crude extracts; however there is no research work for the assessment of total phenolic content determination and antioxidant activity of Averrhoa bilimbi fruits using its different fractions. So our present study is aimed to investigate total phenolic content and antioxidant activity of methanolic extract of Averrhoa bilimbi fruits and its different fractions.

\section{MATERIALS AND METHODS}

\section{Collection and identification}

The fruits of Averrhoa bilimbi were collected from daudkandi, Comilla, Bangladesh on July, 2012. After collection, fruits were thoroughly washed with water, sliced with a knife and dried under sun. The plant was identified and authenticated by Taxonomist of the National Herbarium of Bangladesh, Mirpur, Dhaka (Accession number: DACB 37752).

\section{Preparation, extraction and fractionation}

Cold maceration technique was used for extraction. The dried and powdered fruits $(500 \mathrm{~g})$ were soaked in $2500 \mathrm{ml}$ of methanol for about 15 days at room temperature with occasional stirring. After 15 days the solution was filtered using filter cloth and Whatman's filter paper. The filtrate (methanol extract) obtained was evaporated under ceiling fan and in a water bath below $40^{\circ} \mathrm{C}$ until dried. It rendered a brown granular compound. The brown granular compound was designated as crude extract of methanol.
The concentrated methanol extract was separately partitioned by the modified Kupchan method (Vanwagenen et al., 1993) using pet-ether, carbon tetrachloride, and chloroform. The aqueous methanolic fraction was preserved as aqueous fraction. All the four fractions were evaporated to dry by keeping 7 days in room temperature.

\section{Phytochemical screening}

Phytochemical properties of different extractives of plant materials were tested using the following chemicals and reagents according to the method of Trease and Evans (1989): Alkaloids with Mayer and Dragendoff's reagents, Tannin $\left(\mathrm{FeCl}_{3}\right)$, Saponins (foaming test), Flavonoids (chip of magnesium and $\mathrm{HCl})$, Glycosids $(\mathrm{NaCl}$, and Felhing's solutions A and B), Sterols and Triterpens (ethylic, sulphuric acid and anhydride acetic), Phenols $-\mathrm{FeCl}_{3}$ and $\mathrm{K}_{3} \mathrm{Fe}\left(\mathrm{CN}_{6}\right)-$, Cardiac glycosides (aceticacetic, $\mathrm{FeCl}_{3}$, concentrate sulphuric acid, carbohydrate (alcoholic $\alpha$-naphthol solution, Benedict's reagent).

\section{Determination of total phenolic content}

Total phenolic content of fruits of A. bilimbi extractives was measured employing the method (Demiray et al., 2009) involving Folin-Ciocalteu reagent as oxidizing agent and gallic acid as standard (Majhenic et al., 2007). Different Gallic acid solution were prepared having a concentration ranging from $50 \mu \mathrm{g} / \mathrm{ml}$ to $0 \mu \mathrm{g} / \mathrm{ml} .2 .5 \mathrm{ml}$ of FolinCiocalteau reagent (diluted 10 times with water) and $2.0 \mathrm{ml}$ of $\mathrm{Na}_{2} \mathrm{CO}_{3}(7.5 \% \mathrm{w} / \mathrm{v})$ solution was added to $0.5 \mathrm{ml}$ of Gallic acid solution. The mixture was incubated for 20 minutes at room temperature. After 20 minutes the absorbance was measured at 760 $\mathrm{nm}$. After plotting the absorbance in ordinate against the concentration in abscissa a linear relationship was obtained which was used as a standard curve for the determination of the total phenolic content of the test samples. In $0.5 \mathrm{ml}$ of extract solution (conc. $2 \mathrm{mg} / \mathrm{ml}$ ), $2.5 \mathrm{ml}$ of Folin-Ciocalteu reagent (diluted 10 times with water) and $2.0 \mathrm{ml}$ of $\mathrm{Na}_{2} \mathrm{CO}_{3}(7.5 \%$ w/v $)$ solution was added. The mixture was incubated for 20 minutes at room temperature. After 20 minutes the absorbance was measured at $760 \mathrm{~nm}$ by UVspectrophotometer and using the standard curve prepared from gallic acid solution with different concentration, the total phenolic content of the sample was measured. The phenolic contents of the 
Table 1: Results of phytochemical screening of different extractives of Averrhoa bilimbi fruits.

\begin{tabular}{|c|c|c|c|c|c|}
\hline Test & MEF & PTSF & CTSF & CSF & AQSF \\
\hline Alkaloid & + & + & - & + & + \\
\hline Tanin & + & + & + & - & - \\
\hline Saponins & + & + & - & - & + \\
\hline Flavonoids & + & + & + & + & + \\
\hline $\begin{array}{c}\text { Cardiac } \\
\text { glycosides }\end{array}$ & + & + & - & + & + \\
\hline Glycosides & + & + & + & + & + \\
\hline Phytosterols & - & - & - & - & - \\
\hline Triterpenes & + & + & - & + & - \\
\hline Phenols & + & + & + & + & + \\
\hline Carbohydrate & + & - & + & + & + \\
\hline
\end{tabular}

sample were expressed as mg of GAE (gallic acid equivalent) / gm of the extractive.

\section{DPPH free radical scavenging activity}

The free radical scavenging activity of the extract, based on the scavenging activity of the stable 1, 1diphenyl-2- picrylhydrazyl (DPPH) free radical, was determined by the method described by Braca et al. (2001). $2.0 \mathrm{ml}$ of a methanol solution of the extract at different concentration (500 to $0.977 \mu \mathrm{g} \mathrm{ml}$ ) were mixed with $3.0 \mathrm{ml}$ of a DPPH methanol solution $(20 \mu \mathrm{g} / \mathrm{ml})$. After 30 minutes reaction period at room temperature in dark place the absorbance was measured against at $517 \mathrm{~nm}$ against methanol as blank by UV spectrophotometer. The percentage inhibition activity was calculated from [( $\left.\left.\mathrm{A}_{0}-\mathrm{A}_{1}\right) / \mathrm{A}_{0}\right]$ $\times 100$, where $A_{0}$ is the absorbance of the control, and $A_{1}$ is the absorbance of the extract/ standard. Then the inhibition curves were prepared and IC 50 values were calculated. BHT was used as positive control.

\section{RESULTS AND DISCUSSION}

\section{Phytochemical screening}

The preliminary phytochemical investigation showed the presence of phytochemical constituents such as alkaloid, tanin, saponins, flavonoids, cardiac glycosides, triterpenes, phenols, carbohydrate but absence of phytosterols in different extractives (Table 1). Huda et al., 2009 also found the presence of flavonoids, and triterpenes in the fruits extract of
Table 2: Results of total phenolic content of different extractives of Averrhoa bilimbi fruits.

\begin{tabular}{cc}
\hline Extractives & $\begin{array}{c}\text { Total phenol content } \\
\text { (mg of GAE /g of extractive) }\end{array}$ \\
\hline MEF & $65.16 \pm 0.52$ \\
CTSF & $55.31 \pm 1.01$ \\
CSF & $52.00 \pm 0.90$ \\
PTSF & $68.67 \pm 0.94$ \\
AQSF & $50.23 \pm 0.56$ \\
\hline
\end{tabular}

Values are the mean of duplicate experiments and represented as mean $\pm \mathrm{SD}$. GAE $=$ Gallic acid equivalents

A. bilimbi. The presence of phenols, flavonoids and tannins in all the plants is likely to be responsible for the free radical scavenging effects observed. Flavonoids and tannins are phenolic compounds and plant phenolics are a major group of compounds that act as primary antioxidants or free radical scavengers (Polterait, 1997).

\section{Total phenolic content}

Previously, it is mentioned that the phytochemical screening of the extractives revealed the presence of flavonoid, tannin and phenol. Polyphenolic compounds, like flavonoids, tannins and phenolic acids, usually found in plants have been reported to have multiple biological effects, including antioxidant activity. Flavonoids and tannins present in the plant extract, as evident from phytochemical screening, may be responsible for the antioxidant action in the tested models. The result of total phenol content of the plant extractives is presented in Table 2. The result is expressed as the number of gallic acid equivalents per gram of the plant extractives. Different extractive possesses total phenolic content ranging from 50.23-68.67 mg of GAE /g of extractive.

\section{DPPH free radical scavenging activity}

The DPPH free radical scavenging activity is based on the ability of 1, 1-diphenyl-2-picryl-hydrazyl (DPPH), a stable free radical, to be decolorized in the presence of antioxidants (Kumarasamy et al., 2007). The DPPH radical contains an odd electron, which is responsible for the absorbance at 515-517 $\mathrm{nm}$ and also for visible deep purple color. When DPPH accepts an electron donated by an antioxidant compound, the DPPH is decolorized which can be quantitatively measured from the changes in absorbance (Subhan et al., 2008). 
Table 3: Results of DPPH free radical scavenging activity of different extractives of Averrhoa bilimbi fruits with BHT.

\begin{tabular}{cc}
\hline Extractives & IC $_{50}(\mu \mathrm{g} / \mathrm{ml})$ \\
\hline MEF & 30.365 \\
CTSF & 36.708 \\
CSF & 32.852 \\
PTSF & 50.35 \\
AQSF & 79.918 \\
BHT & 19.656 \\
\hline
\end{tabular}

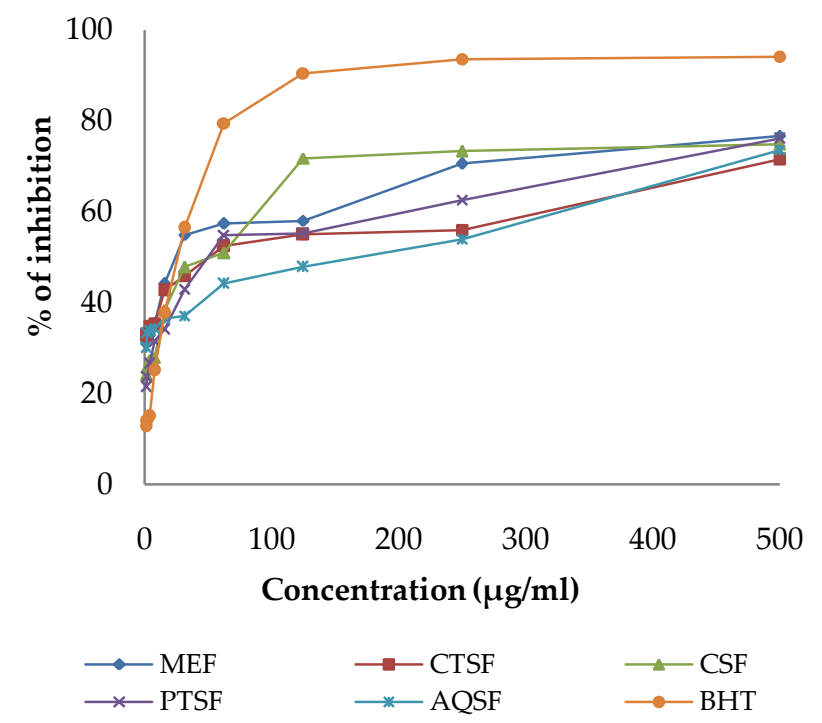

Figure 1: Comparative DPPH radical scavenging activity of different extractives of Averrhoa bilimbi fruits along with BHT.

Five extractives exhibited considerable DPPH free radical scavenging activity as indicated by their $\mathrm{IC}_{50}$ values and this has been showed in Table 3 . IC 50 Indicate the potency of scavenging activity. Standard BHT was found to have an $\mathrm{IC}_{50}$ of $19.656 \mu \mathrm{g} / \mathrm{ml}$. In comparison to BHT, methanol, carbon tetrachloride, pet-ether and chloroform soluble fraction displayed $\mathrm{IC}_{50}$ of $30.365 \mu \mathrm{g} / \mathrm{ml}, 36.708 \mu \mathrm{g} / \mathrm{ml}, 50.35 \mu \mathrm{g} / \mathrm{ml}$ and $32.852 \mu \mathrm{g} / \mathrm{ml}$, respectively. Aqueous soluble fraction is seen to have the least free radical scavenging activity. From above experiment, it can be mentioned that, different extractives of Averrhoa bilimbi fruits may possess significant DPPH free radical scavenging activity due to presence of flavonoid and tannin. Figure 1 shows the DPPH free radical scavenging activity of BHT and different extractives.

\section{CONCLUSION}

From the study it may be concluded that Averrhoa bilimbi fruits is a good source of phytochemicals. Different extractives showed significant DPPH free radical scavenging activity and total phenolic content. Hence, further studies are suggested to be undertaken to pinpoint the exact compound(s) and to better understand the mechanism of such actions scientifically.

\section{REFERENCES}

Aruoma O.I. (1996). Assessment of potential prooxidant and antioxidant actions J. Am. Oil Chem. Soc. Volume 73, Issue 12, Pages 1617-1625. [DOI]

Braca, A., Tommasi, N.D., Bari, L.D., Pizza, C., Politi, M. and Morelli, I. (2001) Antioxidant principles from Bauhinia tarapotensis. Journal of Natural Products. Volume 64 Issue 7, Pages 892-895. [DOI] PMid: 11473417

Choi H.R., Choi J.S., Han Y.N., Bae S.J. and Chung H.Y., (2002). Peroxynitrite scavenging activity of herb extracts. Phytother. Res. Volume 16, Issue 4, Pages 364-367. [DOI]

Demiray, S., Pintado, M.E. and Castro, P.M.L. (2009) ,Evaluation of Phenolic Profiles and Antioxidant Activities of Turkish Medicinal Plants: TiliaArgentea, Crataegi Folium Leaves and PolygonumBistorta Roots". World Academy of Science, Engineering and Technology. Volume 54, Pages 312-317.

Goh, S.H., Chuah, C.H., Mok, J.S.L., Soepadmo, E. (1995). Malaysian medicinal plants for the treatment of cardiovascular diseases.Pelanduk, Malaysia, 63.

Halliwel B., (1994). Free radicals, antioxidants and human disease: curiosity, cause, or consequence? Lancet, Volume 344, Issue 8924, Pages 721-724. [DOI]

Huda N., Wahab A., Wahid M.E.B.A, Taib M., Zuraida W., Zain W.M. and Anwar SA. (2009). Phytochemical screening and antimicrobial efficacy of extracts from Averrhoa bilimbi (Oxalidaceace) fruits against human pathogenic bacteria. Phcog J. Volume 1, Issue 1, Pages 64-66.

Kehrer J.P. and DiGiovanni J., (1990). Comparison of lung injury induced in four strains of mice by butylatedhydroxytoluene. Toxicol.Lett.Volume52, Issue 1, Pages 55-61. [DOI]

Kumarasamy, Y., Byres, M., Cox, P. J., Jaspars, M.., Nahar, L., Sarker, S. D., (2007). Screening seeds of some Scottish plants for free-radical scavenging activity. Phytotherapy Research. Vplume 2, Issue 7, Pages 615-621. [DOI]

Kupchan S.M., Tsou G., (1973). Bruceantin: A new potent antileukemicsimaroubolide from Bruceaantidysenterica. J Org Chem. Volume 38, Issue 1, Pages 178-179. [DOI] PMid: 4682660 
Mackeen M.M., Ali A.M., El Sharkawy S.H., Manap M.Y., Salleh K.M., Lajis N.H., Kawazu K.,(1997). Antimicrobial and cytotoxic properties of some Malaysian traditional vegetables (ulam). International Journal of Pharmacognosy. Volume 35, Issur 3, Pages 174-178. [DOI]

Majhenic, L., Skerget, M. and Knez, Z. (2007) Antioxidant and antimicrobial activity of guaranaseed extracts. Food Chemistry.Volume 104, Issue 3, Pages 1258-1268. [DOI]

Moure A., Cruz J.M., Franco D., Dominguez J.M., Sineiro J., Dominguez H., Nunez M.J. and Parajo J.C., (2001). Natural antioxidants from residual sources. Food Chem Volume.72, Issue 2, Pages 145-171. [DOI]

Polterait O. (1997) Antioxidants and free-radical scavengersof Natural Origin. Current Org. Chem.; Volume 1, Pages 415440.

Pushparaj, P., Tan, C.H., Tan, B.K.H. (2000). Effects of Averrhoa bilimbi leaf extract on blood glucose and lipids in streptozotocin-diabetic rats. Journal of Ethnopharmacology. Volume 72, Issue 1-2, Pages 69-76. [DOI]

Pushparaj, P.N., Tan, B.K., Tan, C.H. (2001). The mechanism of hypoglycemic action of the semi-purified fractions of Averrhoa bilimbi in streptozotocin-diabetic rats.Life Sciences. Volume 70, Issue 5, Pages 535-547. [DOI]
Sawa T., Akaike T. and Maeda H., (2000).Tyrosine nitration by peroxynitrite formed from nitric oxide and superoxide generated by xanthine oxidase.J. Biol. Chem. Volume 275, Issue 42, Pages 32467-32474. [DOI] PMid:10906338

Subhan N., Alam M.A., Ahmed F., Awal M.A., Nahar L., Sarker S.D., (2008). In vitro antioxidant property of the extract of Excoecariaagallocha(Euphorbiaceae). DARU.Volume 16, Issue 3, Pages 149-154. [DOI]

Terao J., Piskula M. and Yao Q., (1994). Protective effect of epicatechin, epicatechingallate and quercetin on lipid peroxidation in phospholipid bilayers.Arch. Biochem. Biophys. Volume 308, Issue 1, Pages 278-284. [DOI] PMid:8311465

Trease, G.E. and W.C. Evans, (1989). Pharmacology 11thEdn., BailliereTindall Ltd., London, Pages 60-75.

Vanwagenen B.C., Larsen R., Cardellina J.H., Ran dazzo D., Lidert Z.C., Swithenbank C., (1993) Ulosantoin, a potent insecticide from the sponge Ulosaruetzleri. J Org Chem. Volume 58, Issue 2, Pages335-337. [DOI]

Yildirim, A., Mavi, A. and Kara, A.A. (2001). Determination of Antioxidant and Antimicrobial Activities of RumexcrispusL. Extracts. Journal of Agricultural and Food Chemistry. Volume 49, Issue 8, Pages 4083-4089. [DOI] PMid:11513714 